\title{
e-Assessment for Learning (eAfL) in higher education: is it a wolf in sheep's clothing?
}

\section{Jennifer Charteris}

University of New England, Australia

\section{Frances Quinn}

University of New England, Australia

\section{Mitchell Parkes}

University of New England, Australia

\section{Peter Fletcher}

University of New England, Australia

\section{Vicente Reyes}

University of New England, Australia

\section{Abstract}

As an extensive body of research demonstrates, Assessment for Learning (AfL) practices can have a significant impact on student achievement in the schooling sector and over the last decade these practices have gained currency in higher education settings. Digital technologies are increasingly being embedded into university programmes, therefore it is important that the issue of quality learning as socio-political engagement in online higher education settings be carefully examined. In this article the authors, a group of pre-service teacher educators who work with students undertaking initial teacher training, explore key discourses that underpin the application of AfL in higher education digital contexts - eAfL (e-Assessment for Learning). In particular, we critique discourses of 'learnification', 'responsibilisation' and 'performativity' in relation to eAfL. We pose possibilities to be considered for the development of robust practices that promote agency and engage with students' funds of knowledge, as the socially and culturally located knowledge, skills and dispositions that learners bring to higher education contexts. 
Keywords: eAfL; ICT; pre-service teachers; higher education; e-learning; e-pedagogy; assessment; formative assessment; assessment for learning.

\section{Introduction}

Much has been written about Assessment for Learning (AfL) in the schooling sector, and there is a growing body of literature on AfL in higher education (Bloxham and Boyd, 2007; Sambell et al., 2012; Boud and Malloy, 2013). However, e-Assessment for Learning (eAfL), as AfL practices in digital contexts, is an emerging but as yet under theorised field of scholarship in higher education. The purposes underpinning assessment and the practices that we adopt need to be carefully considered. Hall and Burke (2004) highlight the determinism of assessment practices by way of a marine metaphor. They suggest that our nets determine what we catch, what we assess is what we get and what we value is what we assess. In this article we examine our 'nets' in reference to eAfL practices.

The authors are a group of pre-service teacher educators (lecturers) who provide initial teacher training in a regional Australian university, the University of New England. Our courses are predominantly accessed online and as teachers firmly situated in a suite of interrelated digital contexts, we are interested in exploring and critiquing eAfL practices. We aim for e-pedagogies that are commensurate with the wider socio-political goals envisaged for higher education, such as enhanced opportunities and equity, and personal and social transformation.

Hence we seek to effectively leverage e-learning environments to produce opportunities for eAfL, where our learners can take ownership of their learning in ways that effectively connect and engage with their personal knowledge. Digital environments, as evolving spaces, are rich in that they enable learners to take up opportunities to do new things in new ways. Online learning can be a generative process that is responsive to students' funds of knowledge (Moll et al., 1992; Gale and Parker, 2014) and promotes their active participation as political citizens. Funds of knowledge are more than a transactional resource of cultural capital in that they comprise the wide and varied resources that are possessed by learners and pertain to the understandings and practices that adult learners bring to learning contexts (Oughton, 2010). 
As educators, we also acknowledge the important role universities play in developing citizens who can think critically and exercise agency. Agency is conceptualised in this paper as dynamic and dispositional, especially evident when learners make moves to initiate learning as active decision makers. We view that Biesta's (2013) emphasis on action and responsibility, or agency, is embedded in an interpretation of assessment for learning that encompasses the 'spirit of assessment for learning' (Marshall and Drummond, 2006, p.137) and engages with learners' funds of knowledge. This is a fluid and responsive approach to assessment practices where educators engage learners as active, agentic participants rather than take up a set of formulaic practices to provide mechanistic feedback.

Nevertheless, teachers in higher education also (to varying extents, inadvertently and purposively) deploy technicist practices that sometimes constrain our students to narrow subject positions as 'objects to be moulded' (Biesta, 2013, p. 1). We observe that the implementation of AfL through digital technologies (eAfL) has been embraced and enacted in current higher education as a discourse of performativity (Ball, 2003). In this paper we critique a technicist deployment of AfL through digital technologies in higher education online environments. We argue that eAfL can support epistemological plurality and diversity but, like a potential wolf in sheep's clothing, it can also be a key tool for massification; a process that prioritises quantity over quality and contributes to the ongoing commodification of higher education. The paper commences with an outline of literature on AfL and eAfL, which we then discuss in the specific context of online higher education. We then critique the discourses of learnification, performativity and power surrounding eAfL in higher education.

\section{Assessment for Learning and formative assessment}

In navigating assessment literature, it is vital to acknowledge a range of different conceptions of Assessment for Learning (AfL). While formative assessment includes the formal and informal processes that both teachers and students use to gather evidence for the improvement of learning (Stiggins and Chappuis, 2006; Chappuis, 2009), AfL also comprises the explicit purpose of students' active participation in the learning process. We deploy the term AfL, preferring it over 'formative assessment', as it evokes the centrality of the learner in the learning process. As some authors use the two terms interchangeably, 
and as the concepts are interrelated, we have included formative assessment in our examination of relevant literature in this section.

The term formative assessment originates from the work of Michael Scriven (1967). For Scriven, formative evaluation was intended to provide information, for both teacher and student, about the progress (or lack of progress) of a student, so that corrective action, if needed, could be taken to help achieve the desired learning outcome. Formative practices have come to the fore in recent years, epitomised by a suite of detailed high profile metaanalyses. The first of these was Terry Crooks' (1988) exploration of 241 articles on 'classroom evaluation'. This seminal study first cast light on the relationships between classroom evaluation practices and student achievement, with particular attention to outcomes involving learning strategies, motivation, and achievement. Ten years later, Black and William (1998) conducted their meta-analysis of 250 research studies to conclude that formative assessment has a large and consistently positive effect on students' learning. Hattie's (2009) influential publication 'Visible Learning; a synthesis of over 800 meta-analyses relating to achievement' supported previous findings, pinpointing the importance of deploying practices that develop 'assessment-competent' learners. These influential studies have served to place AfL in common parlance as an important research-based process that can raise student achievement and engage learners in a knowledge transaction.

Redecker and Johannessen (2013) contextualise formative assessment within 'Knowledge Economy' literature that centres on the notions of change and continuous improvement, pointing out that:

[...] formative assessment is a central feature of the learning environment of the 21st century. Learners need substantial, regular and meaningful feedback; teachers need it in order to understand who is learning and how to orchestrate the learning process. (Redecker and Johannessen, 2013, p.79)

Sambell et al. (2012) observe that when feedback processes are embedded within the process of learning and teaching itself, they are often seen as almost a by-product of the students' engagement with the formal delivery of a course. For those who associate feedback with a formal process, these powerful learning-oriented interactions do not seem like feedback at all (Sambell et al., 2012). Stiggins et al. (2004) describe assessment for 
learning as a range of practices that are designed to address students' information needs to maximise both motivation and achievement, by involving students from the start in their own learning.

In relation to (eAfL), Pachelor et al. (2009) frame approaches to formative e-assessment more widely by including a view of learners as initiators of learning who can both engage with, and transcend, the material mandated within a course structure.

We define formative e-assessment as the use of ICT to support the iterative process of gathering and analysing information about student learning by teachers as well as learners and of evaluating it in relation to prior achievement and attainment of intended, as well as unintended learning outcomes, in a way that allows the teacher or student to adjust the learning trajectory. (Pachelor et al., 2009, p.1)

Thus, the assessment for learning afforded by ICTs can be viewed, both theoretically and in practice, as an important and emerging area of scholarship in higher education. For example, in her review of formative assessment literature in higher education, Evans (2013, p.107) recommends scope for further research into:

The nature of feedback networks, communication flows, and consideration of the attributes of effective feedback seekers [and] the nature and role of specific tools in assisting the development of co- and self-regulation.

This is clearly signalled as a growth area in the academy (Boud et al., 2010).

\section{eAfL in higher education}

Digital technologies have afforded a range of formative assessment tools and practices, currently predominantly facilitated by Learning Management Systems (LMSs) in online or blended higher education environments. These include short answer quizzes, electronic marking, grading and rubrics, which are routine examples of eAfL that are often deployed mechanistically in a transmissive approach from teacher to student in online environments. In contrast, tools such as asynchronous discussions, and embedded blogs and wikis, 
afford teacher-to student, student-to-teacher and student-to student multidirectional eAfL, through facilitating engagement with content and ideas, discussion, and sharing of meaning. Social media such as Twitter, YouTube and Facebook are also emerging as an alternative, or complement, to traditional LMSs, with potential for students to generate their own self-regulated learning spaces (Personal Learning Environments) which potentially afford meaningful eAfL through connections to peers and sharing of learning (Dabbagh and Kitsantas, 2012). Game-supported learning and virtual worlds can feature inbuilt feedback triggered by player decisions and actions, representing another dimension of eAfL in higher education. Accompanying these technologies is the emerging field of learning analytics. In learning analytics, the 'big data' generated within LMSs are captured and analysed and then can be used to generate formative feedback for students or trigger interventions for those students deemed to be 'at risk'.

There are many key advantages to the use of digital technologies for formative assessment (Pachelor et al., 2009) which have contributed to their widespread adoption in higher education. There is a rapid iteration of learning as a result of speedy feedback. The learner can potentially reflect on and implement digitally facilitated feedback quickly. There is an increased storage capacity in digital learning environments, as both teachers and learners have access to large amounts of data. Automated systems can automatically analyse responses and provide feedback promptly. These digital systems are adaptable in that they generate responses based on student input. Furthermore, communication can be rapid across varied audiences. These forms of communication are semi-permanent and can be shared with other learners to enhance learning. Learners represent their ideas through digital technology use and in doing so shape their own thinking, and potentially positively impact the learning of others. The use of digital artefacts can open up a 'window' (Pachelor et al., 2009, p.37) on the learners' thinking that provides information for both the learners and their teachers. In an e-learning setting, eAfL includes having the skills to extract feedback information from the Internet, the learning environment, the lecturer, and peers.

As an example of 'opening a window', one of the authors encourages his students to provide accompanying podcasts to their written assignments. During these podcasts students 'talk to' their assignments, providing descriptions and justifications on their choices made when completing the assignment. Such a conversation would be difficult to write but as a podcast it becomes an activity in reflection. Students are also invited to 
discuss any insights that they may have gained as a result of having completed the assessment task. They can also suggest possible improvements and identify aspects of the assignment that they could address differently were they to repeat it. The podcasts also provide students with opportunities to identify issues for specific commentary when the tasks are marked. This allows learners to request the sort of feedback that they believe will best meet their needs. This interactive process assists to reposition the student in the centre of the feedback dynamic. Rather than being a passive receiver of feedback, students can demonstrate agency through navigating the feedback process. In this way, eAfL can be seen as a means of learner empowerment and agency, creating an online learning environment replete with affordances for student-centred design.

In our context of primarily distance education, lecturers can facilitate learning through digital technologies that enable them to increase student numbers and raise productivity. The AfL practices we describe in this paper are predominantly mediated electronically, therefore we are continually educating our pre-service teachers by way of the eAfL discourses and practices that we adopt. We additionally acknowledge eAfL as a 'window on thinking' that can be aligned with metacognitive processes. Our students continually make judgments about where they are in relation to benchmarks and criteria. In this respect, Sadler's (1989) widely-acknowledged notion of 'closing the gap' can be represented as a cumulative spiral process, where repeated attempts at assignments are necessary for student proficiency to be developed. Notwithstanding the value of this process, we are mindful of running the risk of losing the rich, dynamic and unstable dimensions of knowledge construction that can accompany a technicist conception of 'gap closing', where knowledge is seen as stable and linear.

We believe that divergent and dialogic approaches to assessment have implications for how eAfL can be characterised in digital settings. There are divergent and dialogic forms of feedback (Askew and Lodge, 2000; Carless et al., 2011) where learners draw from their lifeworld experiences as funds of knowledge to share with their peers. Divergent assessment practices can be characterised by on-going dialogue between, and amongst, learners and teachers. This dialogue can be electronically mediated synchronously, via chat or virtual meeting software, and/or asynchronously via discussion forums, where learners can initiate, respond and ask questions, as well as reply to others (Pryor and Crossouard, 2005). Carless et al. (2011) from a co-constructivist perspective emphasise a dynamic nature of learning, where the lecturer also learns from the student through 
dialogue and participation in shared experiences. Taking this kind of a co-constructivist perspective, learning can be seen as a process where the lecturer also learns from the student through dialogic interaction (Carless et al., 2011).

Despite these advantages and affordances, there are some problematic aspects to eAfL in higher education as embodied by a range of discourses, such as responsibilisation, learnification, performativity and power. We discuss these in the following sections.

\section{Learnification and responsibilisation}

'Learnification' denotes how, in a neoliberal discourse, the term 'learning' has been commandeered conceptually as primarily an economic transaction. Biesta (2009) critiques the rise of the 'new language of learning' that he refers to as the concerning trend of 'learnification' of education. In 2005, he problematised the 'new language of learning' arguing that:

[...] it allows for a redescription of the process of education in terms of an economic transaction, that is, a transaction in which (i) the learner is the (potential) consumer, the one who has certain needs, in which (ii) the teacher, the educator, or the educational institution becomes the provider, that is, the one who is there to meet the needs of the learner, and where (iii) education itself becomes a commodity to be provided or delivered by the teacher or educational institution and to be consumed by the learner. (Biesta, 2005, p.58)

Biesta (2013, p.583) points out how the language of teaching reflects these changes in that there are 'learning environments, students are called learners'... [Furthermore] 'adult education has been rebranded as lifelong learning, and the process of education is described as that of teaching-and-learning'. Rather than adopting a commodified view of learning as the development of human capital, Biesta (2011, p.201) argues for a robust conception on learning as a process embedded in a learning culture where 'dispositions, actions, histories and trajectories of individual students [are] constitutive parts of a learning culture [and] student learning is not simply... an 'outcome' or 'product'... but ... something that shapes and forms the culture'. While Biesta (2012, p.4) acknowledges the place of technical skills, with regard to say driving a car, drilling for oil or learning to fly, he posits that education should resist practices that are strongly oriented toward 'reduction, 
reproduction and closure'. Instead, he argues for a more generative approach, not least because assessment-driven practices can impoverish pedagogy. '[l]t is perhaps not without significance that teaching and pedagogy are increasingly being replaced by and redefined as assessment, thus running the risk of driving the event out of education' (Biesta, 2012, p.4)

Lack of information is not an issue in a 'knowledge-driven economy' as the emphasis is on deploying the skills to define, locate, evaluate, organise and use relevant information to inform one's progress and achievement. Nevertheless, what constitutes valued knowledge can become commodified and narrowly defined through educational transactions. As suggested by the findings of Pachelor et al. (2009), eAfL practices, with their foci on the mechanics of student achievement, and their link with the subject position of 'learner as consumer', are imbued with the potential to streamline and enhance learning. eAfL can therefore be critically construed as an embodiment of learnification discourse.

Like learnification, the discourse of 'responsibilisation' also has problematic overtones in relation to eAfL. Implementation of eAfL practices, such as social media-facilitated personal learning environments (Dabbagh and Kitsantas, 2012), is appealing in that they can enable students to take ownership of their own learning (Hodgson and Pang, 2012) and foster self-regulation. However, there are caveats. The emphasis on self could be seen as 'responsibilisation', namely an increased focus on individual student responsibility, over responsibility for others, with the exception of participation in acts of surveillance and control (Rose, 2003; Davies, 2006). As a neoliberal form of accountability, 'responsibilisation' holds individuals responsible for their learning and deflects the gaze from other elements of the system such as shortcomings of curriculum and summative assessment processes.

\section{Performativity}

Both AfL, and the increasingly prevalent eAfL practices in online higher education contexts, can be construed as performative in that they are situated as a transactional exchange of knowledge in higher education educational economy. Performativity can be regarded as a 'grand narrative' associated with modern capitalist societies where knowledge is a commodity to be produced, exchanged in a buyer-seller market, and 
consumed (Lyotard, 1984; Ball, 2003). Researchers in this scenario are the producers of knowledge, whilst teachers disseminate it. Lyotard (1984, p.51) identified competing purposes for knowledge production in the following way:

The question (overt or implied) now asked by the professional student, the State, or institutions of higher education, is no longer 'Is it true?', but 'What use is it?'. In the context of the mercantilisation of knowledge, more often than not this question is equivalent to: 'Is it saleable?' And in the context of power-growth: 'Is it efficient?'.

The development of more sophisticated educational tools has enhanced the power for increased and improved knowledge production in higher education, so that:

'[T]he acceleration of knowledge production and revolutions in information technology' have contributed to 'knowledge capitalism' as a key driver that underpins the notion of a 'knowledge-driven economy'. (Kauppinen, 2014, p.1)

Learning as performance is an uncomfortable discourse for us. As has been argued elsewhere (Nicol and Macfarlane-Dick, 2006), in many cases higher education courses can be designed in such a way that learning is a performance and 'deep learning' is sidelined as courses progress to simply cover more content with engagement with pedagogical process. This focus on content is exacerbated by pressure to cover prescribed criteria by accrediting agencies, as is common for professional degrees such as education, health and engineering. Nicol and Macfarlane-Dick (2006) suggest that most students therefore have little opportunity to directly use the feedback they receive, especially in the case of planned assignments. Invariably, the students are required to move on to the next assessment task soon after feedback is received.

There is also inherent 'performance' tension when students are positioned as consumers through assessment practices in courses. As educators, the performances and pedagogy of teachers in higher education are assessed by their students, paradoxically by those who are in the throes of transformation themselves. Student evaluations are increasingly used as evidence to ensure that lecturers are performing effectively. Professionally and ethically we are charged with the process of engaging students to experience the deep process of transformational learning, often through pathways that support dissonance and confusion, where students engage with and challenge their beliefs as they think critically. Such 
pedagogy requires deep learning strategies where students often explore, look for hidden and nuanced meanings, and make connections between ideas within and beyond disciplinary boundaries (Quinn, 2011). This is not always comfortable for some students who themselves are pushed by their impending employment prospects to perform in ways measured by institutional grading systems. Often these students want electronic answers to enable them to achieve the next Distinction or High Distinction. However, learning in its fullest sense, can sometimes be facilitated by holding back on 'the answers' to promote more thinking and discussion. This requires students to accommodate a degree of discomfort and frustration that may threaten how lecturers' performance is measured. We thus recognise that there are tensions when education is read as a commodified product, and it can be too easy to assume that familiar consumer mantra that 'the customer is always right'.

\section{Performativity and power}

It has been argued (e.g. Hodkinson et al., 2008) that learning theory often fails to fully incorporate the significance of power, and for this reason we propose that AfL practices need to be explored in light of the power relationships embedded within discourses as 'regimes of truth' (Foucault, 2007). As a concept, 'the gaze' was first coined by psychoanalyst Jacques Lacan to describe how becoming visible to others can make one feel hyper aware (Krips, 2010). Drawing on Bentham's penitentiary concept, Foucault (1977) adapted the idea of the 'panoptic gaze' as a commentary on surveillance. In the push for massification, and concomitant use of easy access online learning, higher education can be seen increasingly as a digitalised panopticon. It allows students to surveil themselves and teachers to surveil students, whilst at the same time they are subject to a performative gaze from both students and managers. Some technological practices, for instance, the emerging field of learning analytics, can be seen as elaborate surveillance devices that can provide data on student and teacher performance.

A panopticon consists of a tower situated at the centre of a large central space and is surrounded by a series of buildings, each cell of which has a window that is clearly visible to the surveillant in the tower. The cells can be seen as 'small theatres in which each actor is alone, perfectly individualised and constantly visible' (Foucault, 1977, p.200). Although the comparison between the modern university and Bentham's panopticon as a 
disciplinary technology (Foucault, 1977) is not new, it is apt in that it is a technique deployed to exercise power at minimal cost or effort. The comparison between market driven approaches to teaching and learning in universities and Foucault's conception of the panopticon is also not new (Shore and Roberts, 1993; Miller and Sabapathy, 2011). Shore and Roberts (1993) writing about higher education almost 20 years ago could be describing the modern university today with its advanced use of 'disciplinary technologies.' 'By inducing a state of conscious and permanent visibility the panopticon' transforms the inmate into the instrument of his own subjugation, and thereby guarantees the automatic functioning of power' (Shore and Roberts, p.199; p.3). Deploying the notion of the 'panoptical gaze', the authors observe that processes of performativity in higher education have become increasingly prevalent through assessment practices that are enhanced through digital media.

The technology of learning analytics was originally used to collect data to assess the efficacy of marketing efforts (Mattingly et al., 2012). Similar to its marketing applications, in higher education contexts, the type of data collected through learning analytics is often restricted to records of mouse-clicks; times and durations of access; and navigation paths (Friesen, 2013). This type of data, although extensive and freely available through Learning Management Systems, is typically not data about learning itself (Friesen, 2013). Moreover, learning is a multidimensional phenomenon, and the complex interplay and interactions between students and content; students and their lecturers, and amongst the students themselves, become lost when reduced to the linear approaches typically associated with learning analytics.

The output of learning analytics is often used to fuel data-driven decision making processes. Using statistical software, mathematical models are generated and, based upon these predetermined values, particular actions may be triggered by the system (Campbell et al., 2007). The most commonly discussed use for learning analytics in the literature provision is currently student feedback (Friesen, 2013). This often means that the system used determines the type of feedback. Such a process raises a number of issues. Firstly, feedback delivered in such a fashion acts to de-centre students from the feedback process. Secondly, it reduces the potential for learner agency, as students are prevented from taking agentic positions in their learning. Thirdly, as a technicist practice, it constrains students to narrow subject positions, portraying them as 'objects to be moulded' (Biesta, 2013, p.1). 
Despite the inability of learning analytics to adequately address student learning needs which are complex and can vary over time and context (Friesen, 2013), the allure of automated instruction, based upon data generated through learning analytics, remains strong. As Biesta (2010, p.13) observes, this is indicative of the rise of a culture of performativity in education and raises the question of:

Whether we are indeed measuring what we value, or whether we are measuring what we can easily measure and thus end up valuing what we (can) measure.

These media developments enable practitioners to survey themselves and invite the gaze of others. Teachers are evaluated through learning analytics and corporate intelligence is used to rate their performances. We have observed that educators can find themselves in a situation where they have to split 'good practice' and performance in the interest of ensuring student 'consumer' satisfaction levels are sustained at a high level. In such situations, educators may adopt reductionist approaches to teaching students, focusing on a linear approach to content. This, one can argue, prioritises compliance over education for positive social transformation. Through performative evaluation teachers can get moulded in their teaching. E-pedagogy is therefore often mediated by balancing the inherent tension of 'meeting the market' and making informed pedagogical decisions.

Similarly, students can find themselves being increasingly surveyed by the digital panopticon. EAfL can become blurred with the e-assessment of activity. For example, increasingly students are expected to make regular contributions online to discussions about formative feedback or peer reviewing. Software may be deployed that monitors this online activity and triggers an alert that is sent to the student and their teachers if students fail to engage with the LMS technology after a nominated period of time. This results in the quantity of interactions being measured to monitor attendance rather than their quality which can give an indication of the students' engagement with learning. It follows that students' learning is potentially moulded through inherent messages about what is measured and valued by such performative processes like this kind of electronic feedback.

As an element of performativity, it is important to critique the individualism embedded in a predominately commodified view of learning. In higher education settings, students, as individuals, are self-regulating subjects positioned as consumers in a globally competitive education market. Conceptualising eAfL purely as a process that can improve learning 
outcomes through the use of digital technologies, can miss an important aspect of ownership and the inclusion of different epistemologies and ontologies. When we adopt this stance we run the risk of locating knowledge as static and transmissible rather than dynamic and negotiated. This is evident in the way that learning and knowledge is conveyed as parcels of information in the following description of the purpose of formative assessment in higher education:

Formative assessment centres on activities by teachers and/or a learner or a group of learners who provide information that yields feedback suitable to make necessary modifications to teaching and learning activities, for example those that lead to the learner having a better understanding of what they are trying to learn, what is expected of them and how to make improvements. (Daly et al., 2010, p.3)

A performative perspective of eAfL is based on meritocratic values and as such encompasses individualistic notions of learning. eAfL can promote immediate and transmissive performance feedback from lecturer to student (Gikandi, 2011). As a mechanistic and linear process, feedback from this perspective can be likened to a supermarket checkout. Feedback itself becomes the proxy for educational quality. There is a focus on the processes involved with the measurement of quality rather than the richness of quality learning as a process.

Rubrics in online marking software such as 'Grademark' (iParadigms, 2014) are a case in point. The use of rubrics can be viewed as a process of making the criteria for assessment transparent. Rubrics can define the parameters for both teachers and students, before, during and after summative assessment tasks, hence enhancing the 'FOR' learning in assessment 'OF' learning. However, marking rubrics can be deployed to transmit perceived requisite knowledge from active lecturer donor to passive student recipient. Unless embedded in the teaching process, the language of rubrics can be ambiguous and students and teachers may therefore imbue them with different meanings. They can also be slavish in their linearity, reducing a complex performance into a quantifiable cage. Of course, well-designed rubrics can act as instruments for eAfL by indicating to students what needs to be done to move beyond their current levels of performance or understanding. They can also become effective mediated tools for eAfL when students coconstruct meanings through exploring exemplars with a rubric as a learning tool. This dialogic approach evokes student agency and funds of knowledge. 
By inviting learners to share their different perspectives through digital technologies, diverse funds of knowledge can be recognised. However, it is too easy to take a 'business as usual' approach to assessment practices in e-learning environments that precludes learners from taking agentic positions in their learning. Thus we highlight the importance of fostering 'action and responsibility' (Biesta, 2013, p.1) through reflexive development of eAfL practice that is responsive to learners' funds of knowledge. EAfL practices can offer a means to create effective environments where learners are actively engaged with valuable experiences (Gikandi, 2011, p.1).

\section{High-agency learning environments}

It is possible to develop agency both by de-centering the instructor in e-learning environments and troubling the neoliberal hegemony of learner-centred responsibilisation. We advocate practices that provide students with time and conceptual and temporal space to play, theorise and reflect their own experiences. This process potentially decentres the subject position of the omnipotent instructor. For instance, draft writing can be shared between students so that there is a range of models and peer feedback is visible to all. These written submissions can allow for students to reflect and consider them in relation to their own writing as a form of self-assessment. In addition, written peer feedback provides dialogic self-assessment if there is scope for further comment from the author.

Collaborative writing of this sort supports a continuous feedback loop that transcends 'episodic [and] mechanistic practice' (Boud and Molloy, 2013, p.699). Collaborative writing can take the form of co-constructed mindmaps or shared writing on Google docs. This form of collaboration can also take the form of jointly constructed annotated bibliographies where students critique sources to decide which references to include in their submission. As a negotiation task the learners become both 'seekers and providers' who give and receive feedback, thus orientating themselves and others to the dimensions of the target performance (Boud and Molloy, 2013). In asynchronous online discussions, dialogic feedback (Yang and Carless, 2013) occurs as learners collaboratively formulate their thoughts and theorise how their experiences link with course content. In this sense, every response in a dialogue is feedback (Game and Metcalfe, 2009). 
'E-tone' is an important feature of digital dialogic spaces. As Carless (2009, p.82) observes, for formative feedback to flourish it 'requires lecturers and students to enter into a relationship of trust in which the former try to provide helpful comments that the latter attempt to use'. We consider that a cornerstone of co-constructivist e-pedagogy is the establishment of a culture of relational trust. Particular attention should be paid to e-tone as written text is inherently slippery and open to interpretation. E-tone is a rich area for further research. We envisage that it is situationally constituted, mediated by content, epedagogy and student cohort characteristics. For example, audio feedback allows for an engagement with e-tone with information that can be framed in a discursive way that can make it more accessible and engaging for students (Parkes and Fletcher, 2014). Although audio feedback can be seen as an expedient way to support massification in higher education through a reduced emphasis on the time consuming production of written feedback, it has been found to increase a sense of connectedness, enhance the social presence of the teacher and afford an opportunity to provide a greater level of detail than written feedback (Parkes and Fletcher, 2014). It has been our experience that audio feedback as a vehicle for e-tone promotes a supportive ethos, in particular when the student is underachieving.

Digital tools lend themselves to different e-pedagogies and ways of framing eAfL. They can provide for diagnostics, analytics and provide opportunities for student agency. This is a 'learning oriented' approach to assessment (Keppell et al., 2015). Focusing on learning oriented practices, Boud and Molloy (2013) highlight (with particular reference to feedback) how active dialogic learning requires a collective orientation. They note that these practices require a reorientation in higher education:

- From an act of teachers to an act of students in which teachers are part (from unilateral to co-constructed; from monologue to dialogue).

- From the almost exclusive use of teachers to that of many others (from single source to multiple sources).

- From an act of students as individuals to one that necessarily implicates peers (from individualistic to collectivist).

(Boud and Molloy, 2013, p.710) 
Through eAfL pathways learners can gain electronic feedback from learning objects and assessment artefacts, peers and teachers to determine their next steps. Monitoring systems, like a progress dashboard, can provide information on performance for students and lecturers. Thus eAfL might be seen as a more sophisticated form of learner empowerment.

As we have pointed out in our exploration of 'learnification', 'responsibilisation' and 'performativity' discourses, the sheep and wolf can appear to be one and the same. It can be difficult to tell at a distance whether assessment practices are engendering learner agency or serving learners in a mechanistic way. It requires scrutiny from e-pedagogues to critically examine whom the e-assessment is best serving. To this end we have posed possibilities for the development of robust practices that promote agency and engage with students' funds of knowledge.

\section{Conclusion}

Digital technologies can afford a mechanised process of knowledge transmission. A transmissive approach to eAfL can align with higher education's neoliberal shift to massification and its associated commodified conception of learning. We problematise engagement with practices that on the surface can appear 'common sense' as effective eAfL processes, yet are underpinned by a narrow view of learning and economic rationalism. Although we critique discourses of 'learnification', 'responsibilisation' and 'performativity' when linked with assessment practices, we are mindful of the potential of eAfL to also support student agency. Even though 'responsibilisation' and 'learnification' are powerful discourses for promoting active learner participation in e-learning environments, we argue that linear forms of eAfL, albeit student-centred, do not necessarily address or even acknowledge learner diversity and funds of knowledge. Through responsive eAfL practices, learners can be repositioned so that they are neither passive respondents nor carefully scripted learning subjects who contribute to a purely transactional eAfL process. Education is a social good and should not be reduced to a mechanism deployed in the production of subjects to be 'moulded' in the interest of economic rationalism. It is in the interests of learners that practitioners engage in professional dialogue to inform and critique e-assessment. There is a challenge to balance the tension between 'good practice' and 'consumer' education, provide effective eAfL and 
evaluate teaching practices that on the surface seem democratic but may in fact be to the detriment of learner agency and epistemological plurality.

\section{References}

Askew, S. and Lodge, C. (2000) 'Gifts, ping-pong and loops - linking feedback and learning', in Askew, S. (ed.) Feedback for learning. London: Routledge Falmer, pp. $1-19$.

Ball, S. (2003) 'The teacher's soul and the terrors of performativity', Journal of Education Policy, 18(2), pp. 215-228.

Biesta, G. (2005) 'Against learning. Reclaiming a language for education in an age of learning', Nordisk Pedagogik, 25(1), pp. 54-66.

Biesta, G. (2009) 'Good education in an age of measurement', Educational Assessment, Evaluation and Accountability, 21(1), pp. 33-46.

Biesta, G. (2011) 'From learning cultures to educational cultures: values and judgements in educational research and educational improvement', International Journal of Early Childhood, 43(3), pp. 199-210.

Biesta, G. (2012) 'No education without hesitation: exploring the limits of educational relations', Philosophy of Education, Issue 2012, pp. 1-13.

Biesta, G. (2013) The beautiful risk of education. London: Paradigm.

Black, P. and Wiliam, D. (1998) 'Inside the black box: raising standards through classroom assessment', Phi Delta Kappan, 80(2), pp. 139-144.

Bloxham, S. and Boyd, P. (2007) Developing effective assessment in higher education: a practical guide. Milton Keynes, UK: Open University Press. 
Boud, D. and Associates (2010) Assessment 2020: seven propositions for assessment reform in higher education. Sydney: Australian Learning and Teaching Council. Available at: http://www.uts.edu.au/sites/default/files/Assessment2020_propositions_final.pdf (Accessed: 25 July 2014).

Boud, D. and Molloy, E. (2013) 'Rethinking models of feedback for learning: the challenge of design', Assessment \& Evaluation in Higher Education, 38(6), pp. 698-712.

Campbell, J.P., DeBlois, P.B. and Oblinger, D.G. (2007) 'Academic analytics: a new tool for a new era', EDUCAUSE Review, 42(4), pp. 41-57.

Carless, D. (2009) 'Trust, distrust and their impact on assessment reform', Assessment \& Evaluation in Higher Education, 34(1), pp. 79-89.

Carless, D., Salter, D., Yang, M. and Lam, J. (2011) 'Developing sustainable feedback practices', Studies in Higher Education, 36(4), pp. 395-407.

Chappuis, J. (2009) Assessment for learning: classroom practices that maximize student success. Available at:

http://d43fweuh3sg51.cloudfront.net/media/media_files/sevenstrategies.pdf (Accessed: 25 July 2014).

Crooks, T. (1988) 'The impact of classroom evaluation practices on students', Review of Educational Research 58(4), pp. 438-481.

Dabbagh, N. and Kitsantas, A. (2012) 'Personal learning environments, social media, and self-regulated learning: a natural formula for connecting formal and informal learning,' The Internet and Higher Education, 15(1), pp. 3-8.

Daly, D., Pachelor, N., Mor, Y. and Mellar, H. (2010) 'Exploring formative e-assessment: using case stories and design patterns', Assessment \& Evaluation in Higher Education, 35(5), pp.619-636.

Davies, B. (2006) 'Subjectification: the relevance of Butler's analysis for education', British Journal of Sociology of Education, 27(4), pp. 425-438. 
Evans, C. (2013) 'Making sense of assessment feedback in higher education', Review of Educational Research, 83(1), pp. 70-120.

Friesen, N. (2013) 'Learning analytics: readiness and rewards', Canadian Journal of Learning and Technology, 39(4), pp. 1-12.

Foucault, M. (1977) Discipline and punish: the birth of the prison. London: Penguin Books.

Foucault, M. (2007) Security, territory, population: lectures at the Collège de France. 1977-1978 (G. Burchell, Trans.). Basingstoke, UK: Palgrave Macmillan.

Gale, T. and Parker, S. (2014) 'Navigating change: a typology of student transition in higher education', Studies in Higher Education, 39(5), pp. 734-753.

Game, A. and Metcalfe, A. (2009) 'Dialogue and team teaching', Higher Education Research and Development, 28(1), pp. 45-57.

Gikandi, J. (2011) 'Achieving meaningful online learning through effective formative assessment', in Williams, G., Statham, P., Brown, N. and Cleland, B. (eds.) Changing demands, changing directions: Proceedings of ascilite Hobart 2011. Hobart, Tasmania, Australia 4-7 December, pp. 452-454 [Online]. Available at: http://www.ascilite.org/conferences/hobart11/downloads/papers/Gikandi-poster.pdf (Accessed: 7 July 2015).

Hall, K. and Burke, W. (2004). Making formative assessment work: effective practice in the primary classroom. Maidenhead, UK: Open University Press.

Hattie, J. (2009) Visible learning: a synthesis of over 800 meta-analyses relating to achievement. London: Routledge.

Hodgson, P. and Pang, M. (2012) 'Effective formative e-assessment of student learning: a study on a statistics course', Assessment \& Evaluation in Higher Education, 37(2), pp. 215-225. 
Hodkinson, P., Biesta, G. and James, D. (2008) 'Understanding learning culturally: overcoming the dualism between social and individual views of learning', Vocations and Learning, 1(1), pp. 27-47.

iParadigms (2014) Smarter grading. Five types of rich feedback on any type of assignment. Available at: http://turnitin.com/en us/features/grademark (Accessed: 25 July 2014).

Kauppinen, I. (2014) 'Different meanings of 'knowledge as commodity' in the context of higher education', Critical Sociology, 40(3), pp. 1-17.

Keppell, M., Suddaby, G. and Hard, N. (2015) 'Assuring best practice in technologyenhanced learning environments', Research in Learning Technology, 23 [Online]. Available at:

http://www.researchinlearningtechnology.net/index.php/rlt/article/view/25728 (Accessed: 27 March 2015).

Krips, H. (2010) 'The politics of the gaze: Foucault, Lacan and Žižek', Culture Unbound: Journal of Current Cultural Research, 2(6), pp. 91-102. Available at: http://www.cultureunbound.ep.liu.se/v2/a06/cu10v2a6.pdf (Accessed: 25 July 2014).

Lyotard, J-F. (1984) The postmodern condition: a report on knowledge. Geoff Bennington and Brian Massumi (trans.). Minneapolis, MN: University of Minnesota Press.

Marshall, B. and Drummond, M. (2006) 'How teachers engage with Assessment for Learning: lessons from the classroom', Research Papers in Education, 21(2), pp. 133-149.

Mattingly, K.D., Rice, M.C. and Berge, Z.L. (2012) 'Learning analytics as a tool for closing the assessment loop in higher education', Knowledge Management \& E-Learning: An International Journal, 4(3), pp. 236-247. 
Miller, N. and Sabapathy, J. (2011) 'Open universities: a vision for the public university in the twenty-first century', in Holmwood, J. (ed.) A manifesto for the public university. London, UK: Bloomsbury, pp. 42-55.

Moll, L., Amanti, C., Neff, D. and González, N. (1992) 'Funds of knowledge for teaching: using a qualitative approach to connect homes and classrooms', Theory into Practice, 31(2), pp. 132-141.

Nicol, D. and Macfarlane-Dick, D. (2006) 'Formative assessment and self-regulated learning: a model and seven principles of good feedback practice', Studies in Higher Education, 31(2), pp. 199-218.

Oughton, H. (2010) 'Funds of knowledge - a conceptual critique', Studies in the Education of Adults, 42(1), pp. 63-78.

Pachelor, N., Mellar, H., Daly, D., Mor, Y., Wiliam, D. and Laurillard, D. (2009) Scoping a vision for formative e-assessment: a project report for JISC. Available at: http://www.jisc.ac.uk/media/documents/projects/scopingfinalreport.pdf (Accessed: 25 July 2014).

Parkes, M. and Fletcher, P.R. (2014) 'Talking the talk: audio feedback as a tool for student assessment', in Proceedings of the World Conference on Educational Multimedia, Hypermedia and Telecommunications, (1), pp. 1606-1615. Tampere, Finland 23-26 June.

Pryor, J. and Crossouard, B. (2005) 'A sociocultural theorization of formative assessment', Sociocultural Theory in Educational Research and Practice Conference. University of Manchester, Manchester 8-9 September.

Quinn, F. (2011) 'Learning in first-year biology: approaches of distance and on-campus students', Research in Science Education, 41(1), pp. 99-121.

Redecker, C. and Johannessen, $\varnothing$. (2013) 'Changing assessment -towards a new assessment paradigm using ICT', European Journal of Education, 48(1), pp. 79-92. 
Rose, N. (2003) Powers of freedom: reframing political thought. Cambridge UK: Cambridge University Press.

Sadler, D. (1989) 'Formative assessment and the design of instructional systems', Instructional Science, 18(2), pp. 119-144.

Sambell, K., McDowell, L. and Montgomery, C. (2012) Assessment for learning in higher education. London: Routledge.

Scriven, M. (1967) 'The methodology of evaluation', in Tyler, R.W., Gagné, R.M. and Scriven, M. (eds.) Perspectives of curriculum evaluation. Chicago, IL: Rand McNally, pp. 39-83.

Shore, C. and Roberts, S. (1993) 'Higher education and the panopticon paradigm: quality assessment as 'disciplinary technology", Society for Research into Higher Education Conference. Brighton, England, 14-16 December [Online]. Available at: http://files.eric.ed.gov/fulltext/ED368243.pdf (Accessed: 31 July 2014).

Stiggins, R., Arter, J., Chappuis, J. and Chappuis, S. (2004) Classroom assessment for student learning: doing it right-using it well. Portland, OR: Assessment Training Institute.

Stiggins, R. and Chappuis, J. (2006) 'What a difference a word makes: assessment FOR learning rather than assessment OF learning helps students succeed', Journal of Staff Development, 27(1), pp. 10-14.

Yang, M. and Carless, D. (2013) 'The feedback triangle and the enhancement of dialogic feedback processes', Teaching in Higher Education, 18(3), pp. 285-297.

\section{Author details}

Dr Jennifer Charteris is a Lecturer in Pedagogy within the School of Education. She teaches research methods at Masters level and learning theories in the B.ED primary course. Jennifer's main research interests are in the area of teacher and student learning/e-learning, identity, agency and critical, postcolonial and poststructural theories. 
Dr Frances Quinn is a member of the Science Education teaching team in the University of New England, School of Education. She teaches science and sustainability, primary and secondary science education, and biology. Her research interests comprise: science education (particularly biology); distance/blended science learning and teaching; students' perceptions of learning science; and education for sustainability.

Dr Mitchell Parkes is Lecturer in ICT Education with the University of New England. He teaches into both undergraduate and postgraduate programmes in the School of Education. Prior to working at UNE, Mitch was a secondary teacher with a teaching background in computing studies, science and mathematics. He is also a qualified Teacher Librarian.

Dr Peter Fletcher is a Lecturer in ICT Education with the University of New England. His career experience includes 16 years in industry based ICT; 15 months post-doctoral experience at Kansas State University in physics education; three years full-time secondary teaching; and five years university teaching, as well as nine years part-time teaching across Technical and Further Education (TAFE NSW), private tuition, Adult Community Education (ACE), secondary school and university settings.

Dr. Vicente Chua Reyes, Jr. is a Lecturer with the School of Education, University of New England. He is co-editor of the Policy and Leadership Studies Working Papers Series of the National Institute of Education (Singapore) and a Fellow of the Centre for Chinese Studies of the Republic of China (Taiwan), the National Taiwan Normal University. Trained as a political scientist, his current research interests are in young people's conceptions of political interest and civic participation. He also pursues research inquiries into educational leadership, issues of corruption and governance, and educational reform. 